Journal of Sustainable Agricultural Sciences
http://jsas.journals.ekb.eg/

استهدف هذا البحث التعرف علي الشكلات التي تعوق أعضاء روابط مستخدمي مياة الري للقيام بدورهم

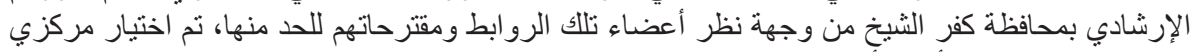

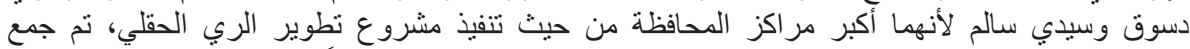

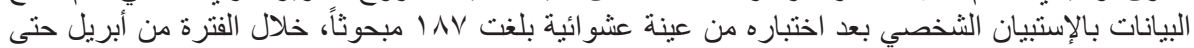

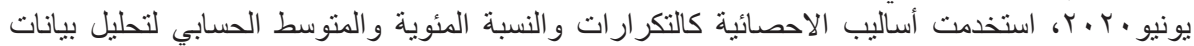

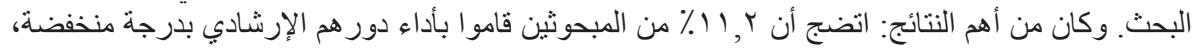

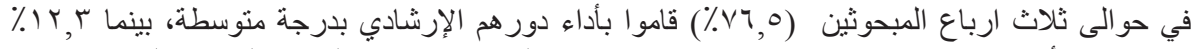

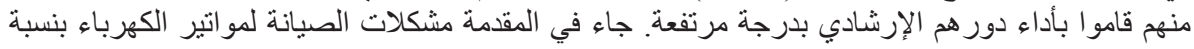

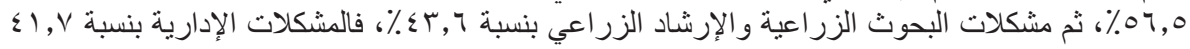

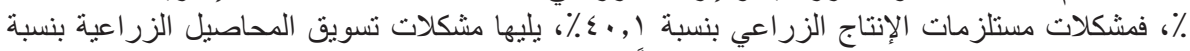

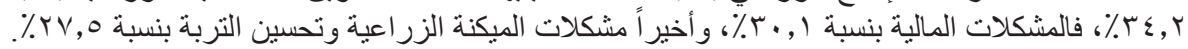

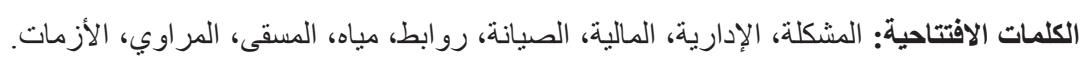

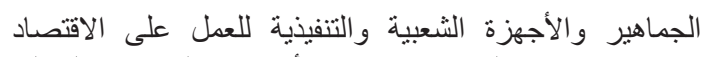

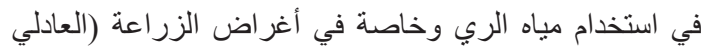

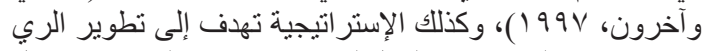

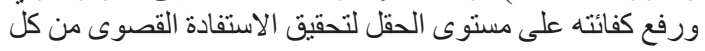

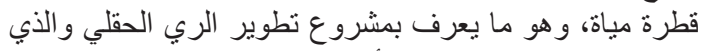

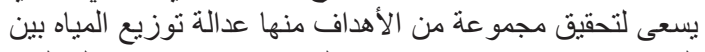

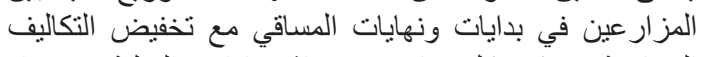
الزر اعية، وتمكين كل مز ارع من مبان وانثرة إدارته الفعلية لاستخدام

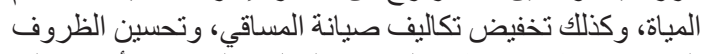

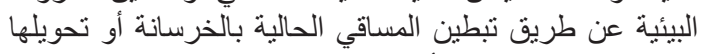

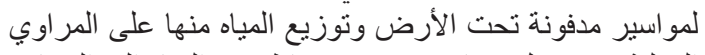

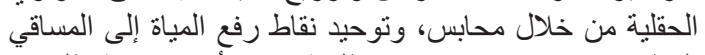

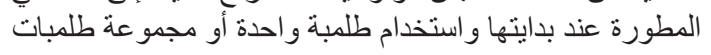
يتم إدارتها وصيانتها بمعرفة الزراع (عنتر ، 1991).

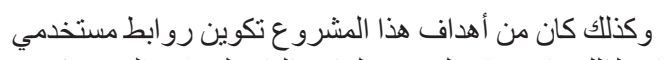

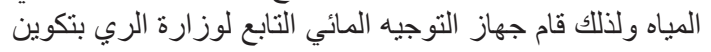

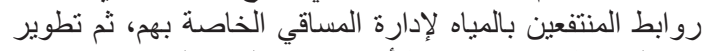

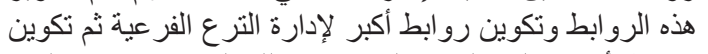

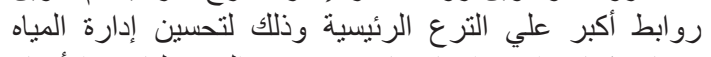

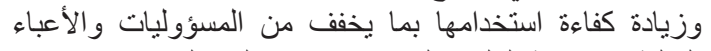

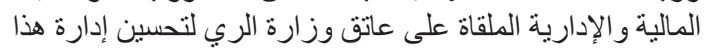

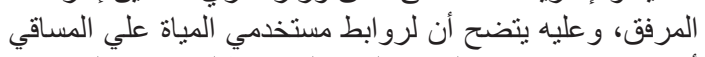
أهمية كبيرة في إدارة المورد المائي ليس فقط لتحقيق عدالة توزيع اليط
المقدمة ومشكلة البحث

يعد القطاع الزراعي هو المسئول عن تحقيق الأمن الغذائي وتلبية

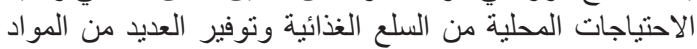

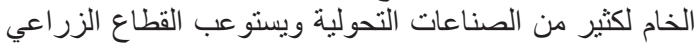

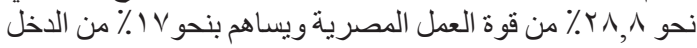

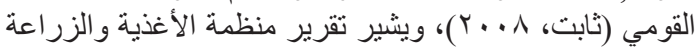

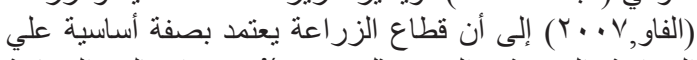

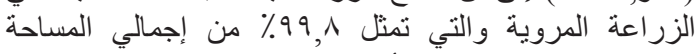

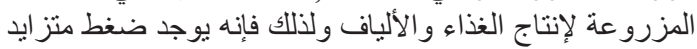

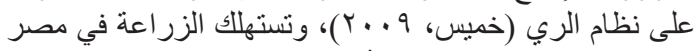

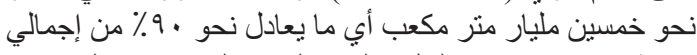

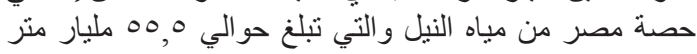

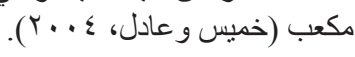

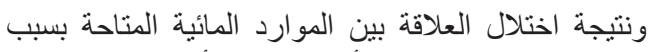

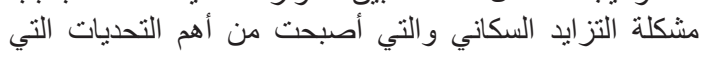

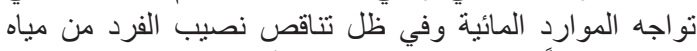

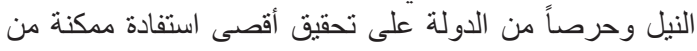

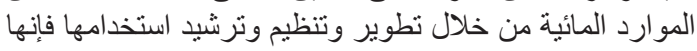

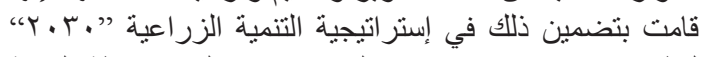

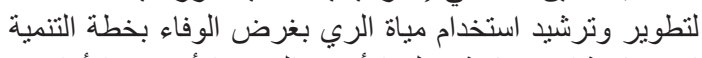

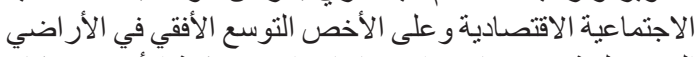

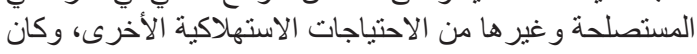
من بين ما تتضمنه تلك الإستر اتيجية محاولة إيجاد وعى لالى الإن 
لاضمن زيادة الإنتاج الزراعي من خلال تحسين الحالة الإنتاجية

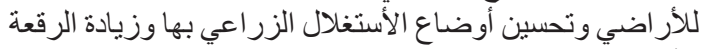

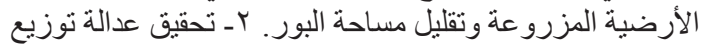

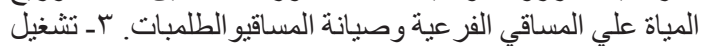
وصيانة ومتابعة المساقي المطورة و والمضخات المبات ـ عـ تحسين أداء

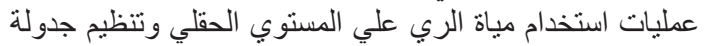
الري. هـ إقناع المزار عين بأهمية إنباع نظم الري الري المنطور.

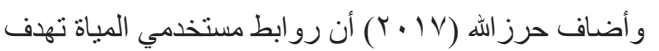

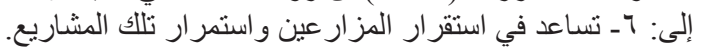

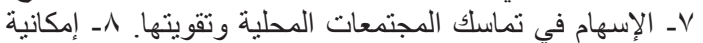

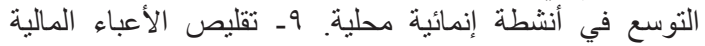
والإدارية عن الحكومات.

يكتسب مفهوم الدور The Role أهمية كبيرة لأنه بيساعد

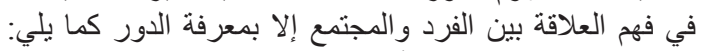

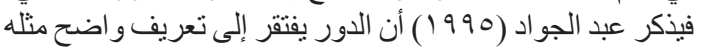

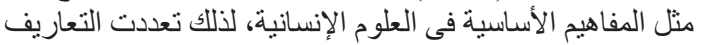

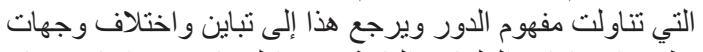

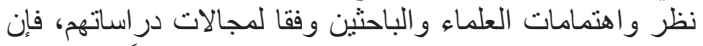

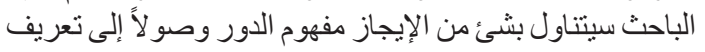

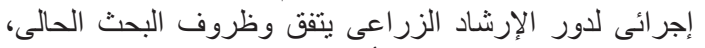

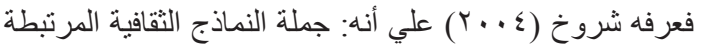

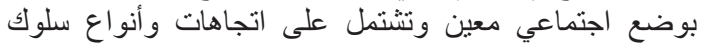

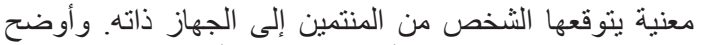

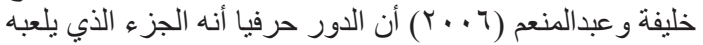

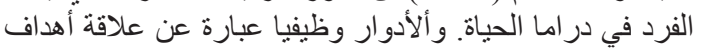

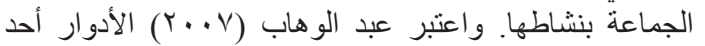

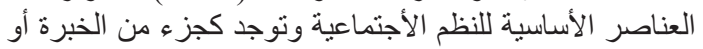
المعرفه المرتبطة بسلو كك أفر اد محددين في مو اقف معينة

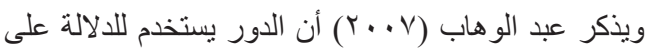

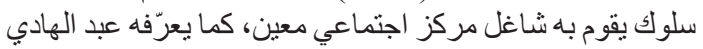

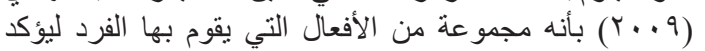

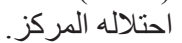

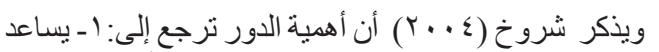

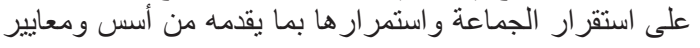

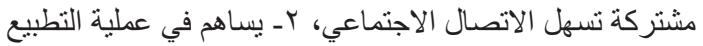

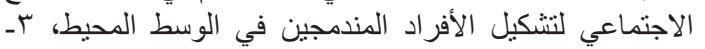

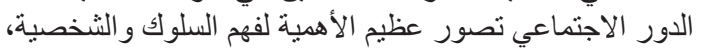

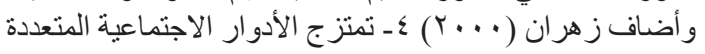

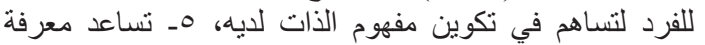

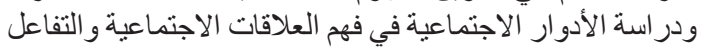

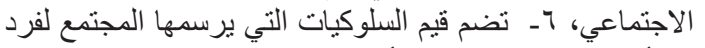

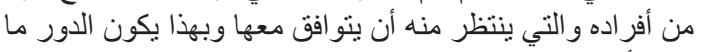

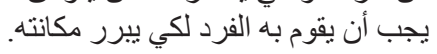

ويوضح الوردي (1999) أن كلمة مشكلة أنساً

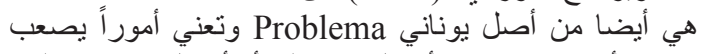

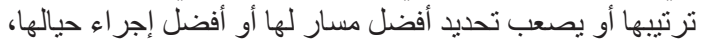

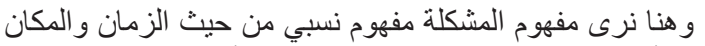

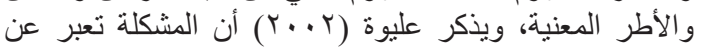

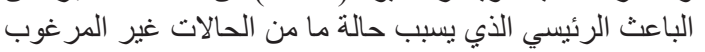

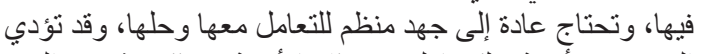
إلى وجود أزمة ولكنها ليست بذاتها أزمة. ويذكر شمس الدين

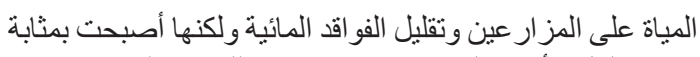

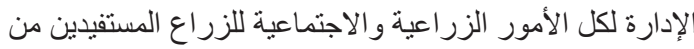

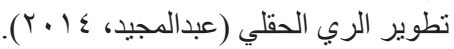

تقع محافظة كفر الشيخ من المحافظات الثمالية فى نهايات

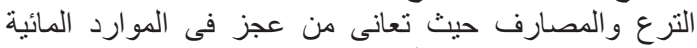

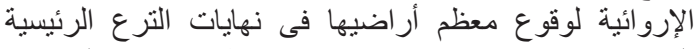

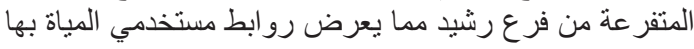

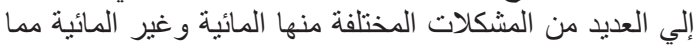

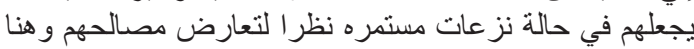
بيرز دور رو ابط مستخدمي المياة علي المساقي في كيفية التغلب علي هذه المشكلات.

وبناء علي ذللك يمكن بلورة مشكلة هذا البحث في عدة

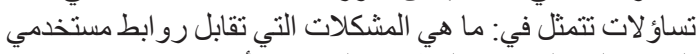

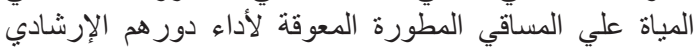

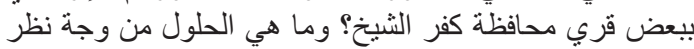
روابط مستخدمي المياة علي المساقي في مواجة هذي هذه المشكلات

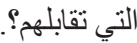

أهداف البحث

يستهدف هذا البحث بصفة رئيسية التعرف علي المشكلات

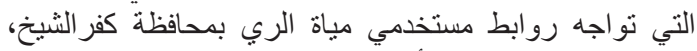
ويتحقيق ذلك من خلال الأهداف الفر عية التنالية:

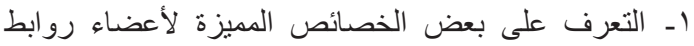
مستخدمي المياه المبحوثين.

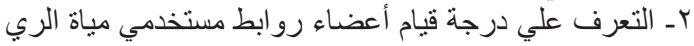

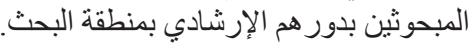

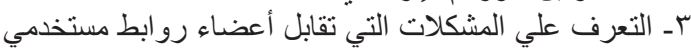
المياة المبحوثين بمنطقة البحثي.

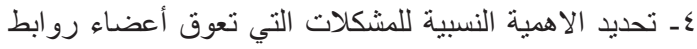

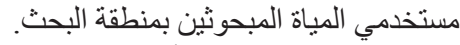

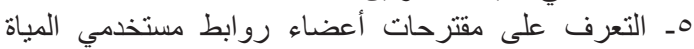
المبحوثين للحد من تلك المشكلات ألتات

\section{الاستعراض المرجعي}

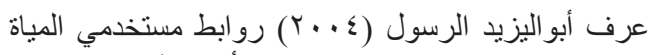
Water Users Association(WUA) أي تقوم به منظمات خاصة غير حكومية مملوكة وتدار بعرفئ

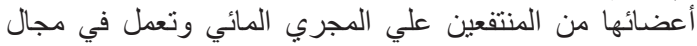

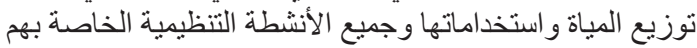

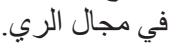

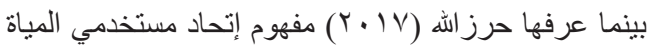

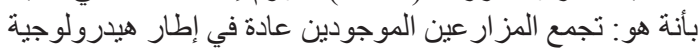

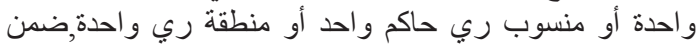

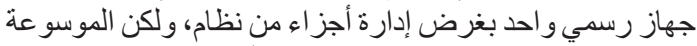

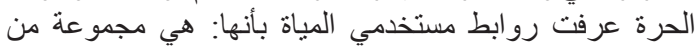

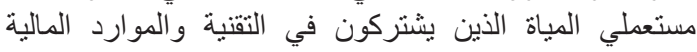

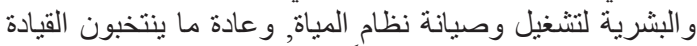

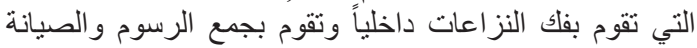

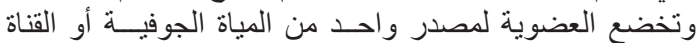
.(https//:Wikipedia org)

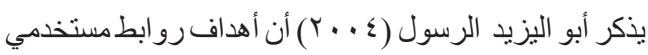

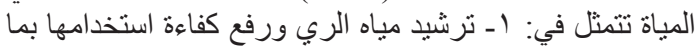

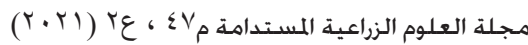


- ارتفاع مستوى معارف وممارسات أعضاء رو ابط مستخدمي

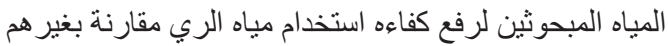
خارج الر ابطة. - وجود فرق معنوي بين أعضاء روابط روبط مستخدمي المياه

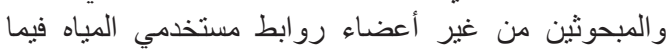

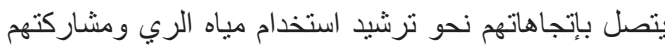
الاجتماعية

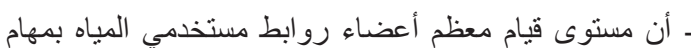
الر ابطة كان مرتفعاً. - يوجد عدة معوقات تواجة المبحوثين عند تتفيذ الممارسات

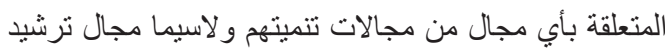

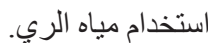

الطريقة البحثية

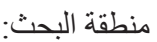

أجري هذا البحث بمحافظة كفر الشيخ حيث يعتمد نشاط غالبية

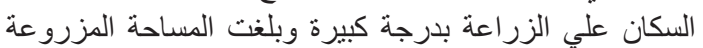

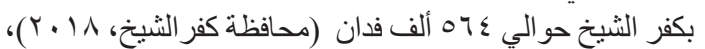

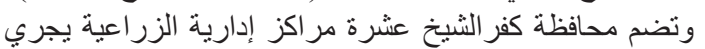

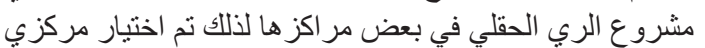

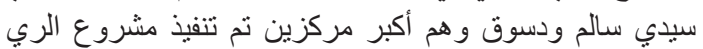
الحقلي بهم علي ثرعة المنايفة وميت يزيد.

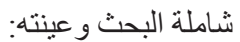

تمثلت شاملة البحث في جميع أعضاء رو ابط مستخدمي مياة

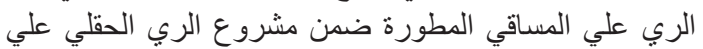

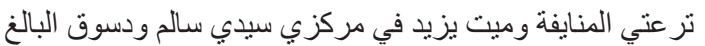

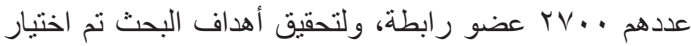

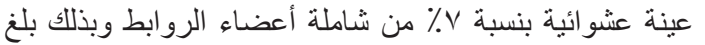

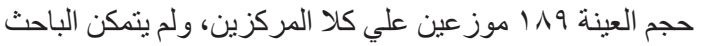

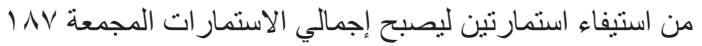
مبحوثاً، ويوضح الجدول التالي توزيع شاملة و عينة البحث.

يتبين من الجدول السابق أن توزيع العينة بمركز سيدي سالم

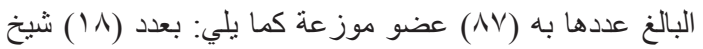

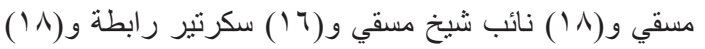

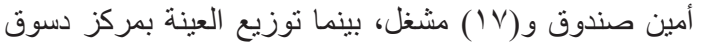

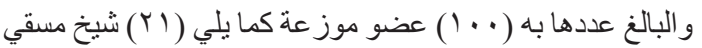

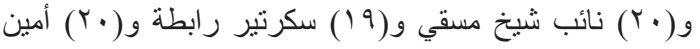

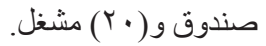

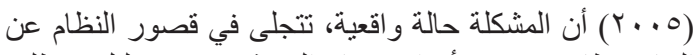

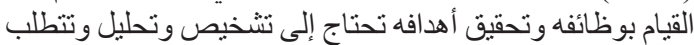

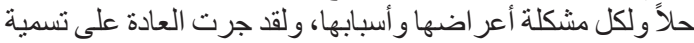
المشكلة التي تخص دولة أو عدة دول (أزمة) فيقال أزمة البطالة التهاء الأزمة الاجتماعية، أزمة الثرق الأوسط...الخ.

ويصنف شمس الدين (0 . . r) المشكلات الإدارية بموجب عدد من المؤشر ات فيما يلي:

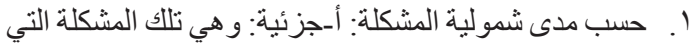
تتعلق بأحد النظم الجزئية المكونة للنظام أو أحد جو انب عمله النه

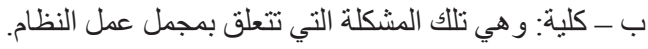

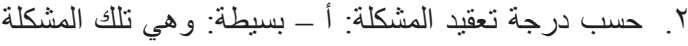

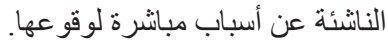

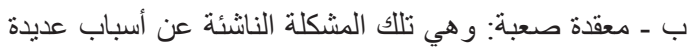

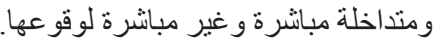

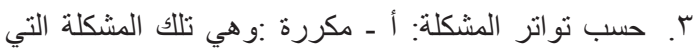

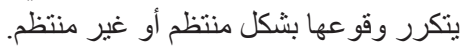

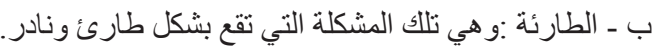

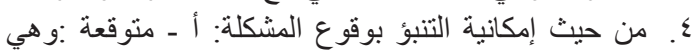

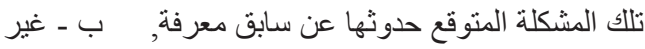

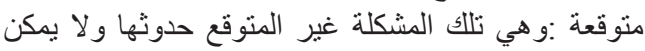
التنبؤ بوقو عها.

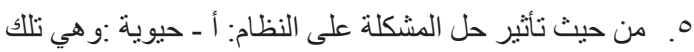

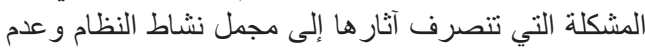

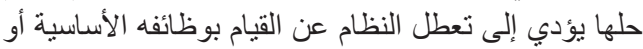

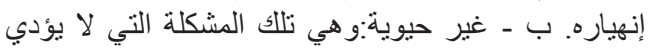

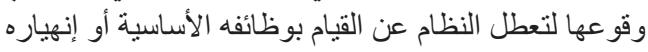

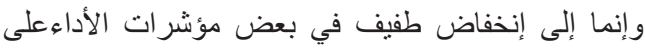

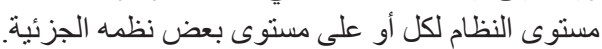

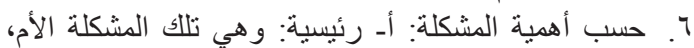

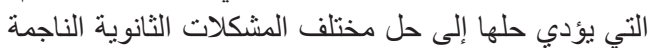

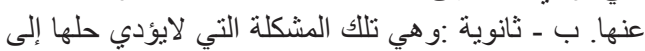

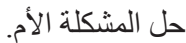

وتوصلت بعض الدراسات في هذا الصدد كدر اسة أبو الخبر

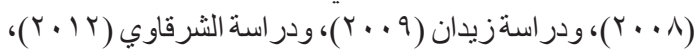

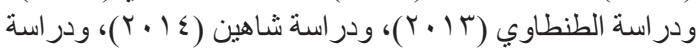

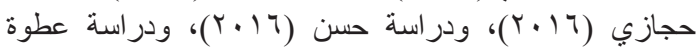

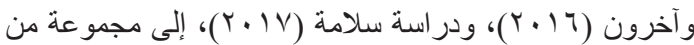

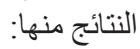

جدول ا ـ توزيع عينة البحث علي مركزي سبدي سالم ودسوق وعلي أعضاء الروابط.

\begin{tabular}{|c|c|c|c|c|c|c|}
\hline المشغل & أمين الصندوق & السكرتير & نائب شيخ المسقي & شيخ المسقي & العينة & المركز \\
\hline IV & 11 & 17 & 11 & 11 & $\Lambda V$ & سيدي سالم \\
\hline$r$. & r. & 19 & r. & YI & $1 \ldots$ & دسوق \\
\hline rv & rᄉ & ro & rᄉ & rq & INV & الإجمالي \\
\hline
\end{tabular}

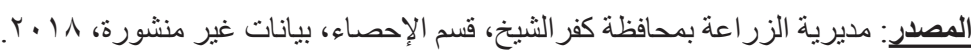


سؤ ال المبحوث عن المعرفة بعدد أعضاء الر ابطة و الجو اب يكون

(نعم) وأعطيث درجات (؟) أو الإجابة (لا) درجات (1) (ل).

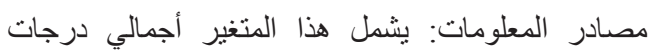

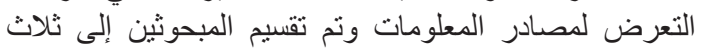
فئات على إجمالي القيمة الحاصل عليها المبحوث من مصادر

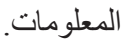

\section{النتائج ومناقشتها}

أو لاً: بعض الخصائص المميزة لأعضاء روابط مستخدمي

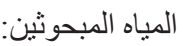

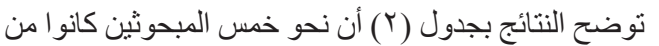

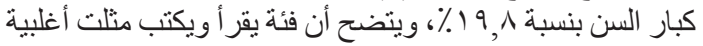

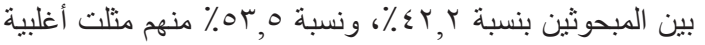

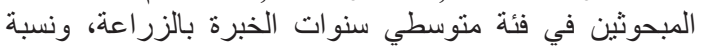

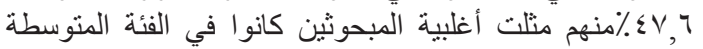

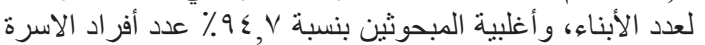

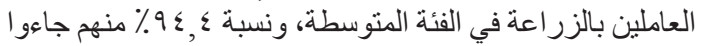
في الفئة المنفضضة من حيث السعة الحيازية المزرعية.

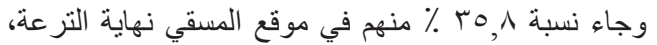

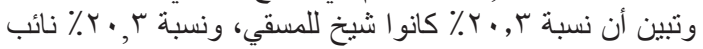

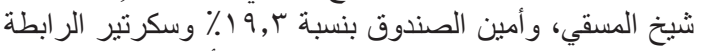

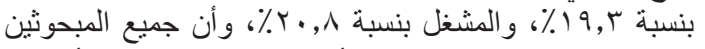
عندهم المعرفة الكاملة بجميع أعضاء الرابطة وابطة وعدد أعضاء

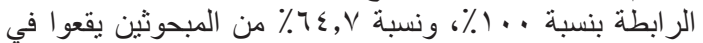

الفئة المتوسطة من حيث مصادر المعلومات، جدول (Y) (؟). ثنانياً: قيام أعضاء روابط مستخدمي مياة الري المبحوثين

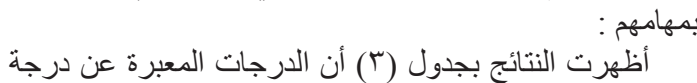

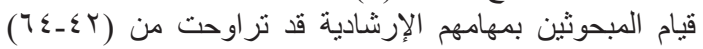

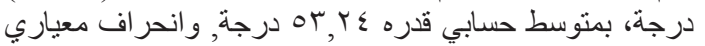

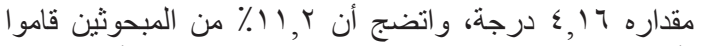

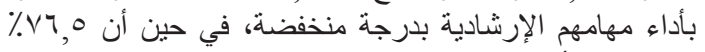

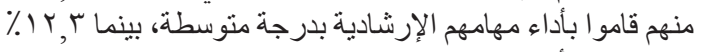
منهم قامو ا بأداء مهامهم الإرشادية بدرجة مهادية مرتفعة.

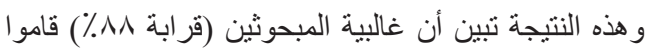

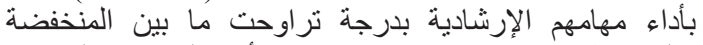

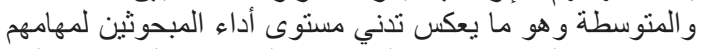

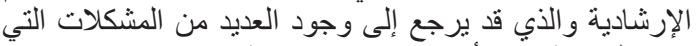
تعيق المبحوثين في أداء مهامهم الإرشادية.

ولمزيد من التوضيح سوف نتناول مدى قيام المبحوثين بكل

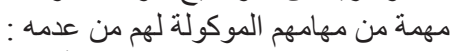

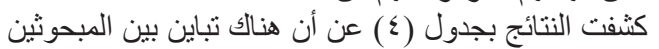

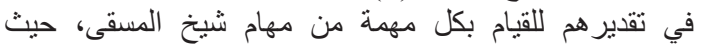

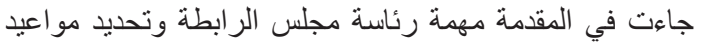

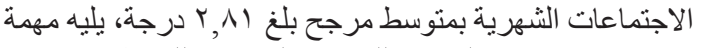

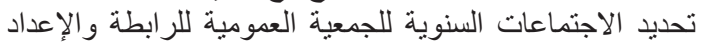

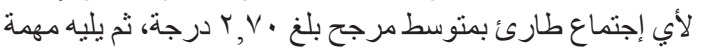

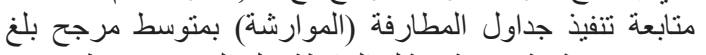

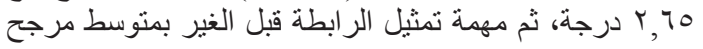

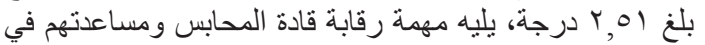

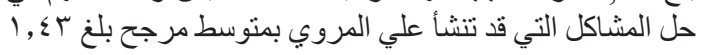

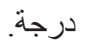

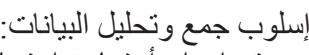

تم إعداد أستمارة أستبيان لأعضاء روابط مستخدمي مياة الري تضمنت عدد من الأسئلة المتعلقة بالمتغيرات المات المستقلة،

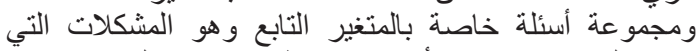
تعوق الدور الإرشادي لأعضاء روبط مستخدمي المياة وما هي التي مقترحاتهم لحل هذه ألمشكلات، وتم اختبار استمارة الاستبيان

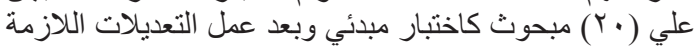

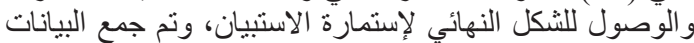

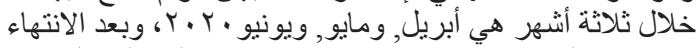

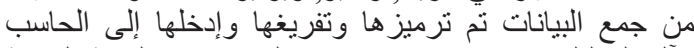

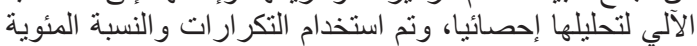
و الدتوسط الحسابي لتحليل وتفسير النتائج. قياس متغير ات البحث:

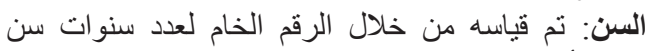

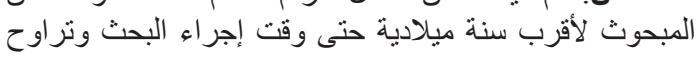

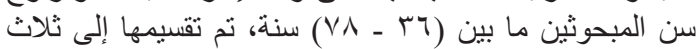

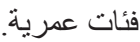

المستوي التعليمي للمبحوث: تم قياسها من خلال إعطاء

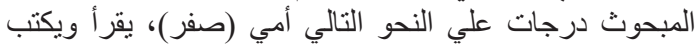

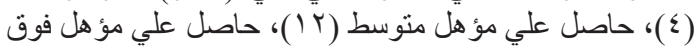
المتوسط (ء (1)، حاصل علي مؤهل جامعي( (1) (1) ).

سنوات الخبرة بالزراعة: تم قياسها من خلال الرقم الخام

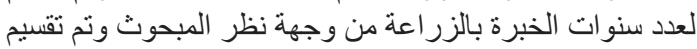
المبحوثين إلى ثلاث فئات منخفضة ومتو سطة ومر تفعة.

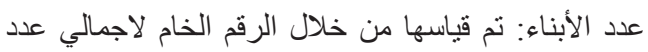

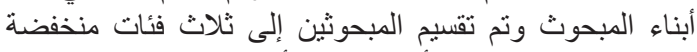
ومتوسطة ومرتفعة علي أساس عدد الأبناء.

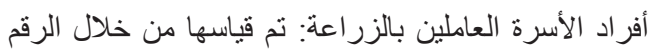

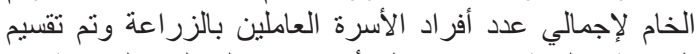

المبحوثين إلى ثلاث فئات علي أساس عدد العاملين بالزر اعة.

السعة الحيازية المزرعية: تم قياس هذا الدتغير من خلال

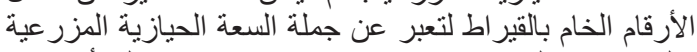

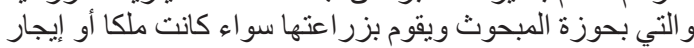

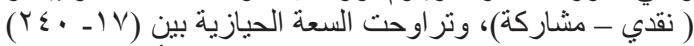
قير اطُ وتم تقسيم المبحوثين إلى ثلاث فئات علي أساس المساحة المزرعية التي بحوزة المبحوث.

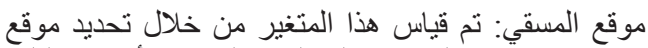

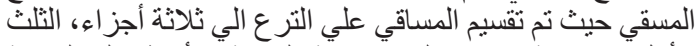

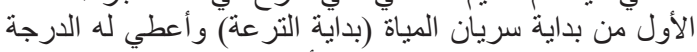

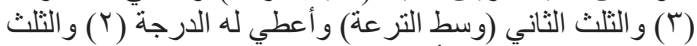

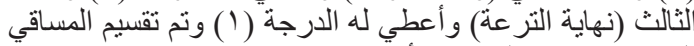
إلى ثلاث فئات علي هذا الأسأس.

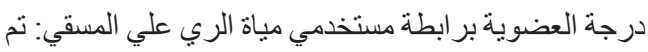

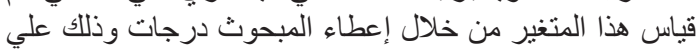

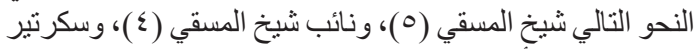

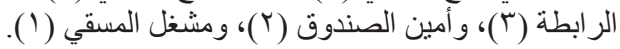

المعرفة بأعضاء الرابطة: تم قياس هذا المتغير من خلال

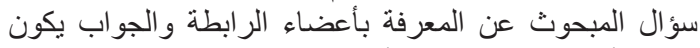
(نعم) و أعطيت درجات (r) أو الإجابة (لان) درجة (1) (1)

المعرفة بعدد أعضاء الر ابطة: تم قياس هذا المتغير من خلال

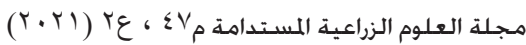


جدول r ـ توزيع المبحوثين وفقاً لبعض الخصائص المميزة لهم .

\begin{tabular}{|c|c|c|c|c|c|}
\hline$\%$ & عدد & الخصائص & $\%$ & عدد & الخصائص \\
\hline \multicolumn{3}{|r|}{ الخبرة بالزر اعة } & \multicolumn{3}{|r|}{ 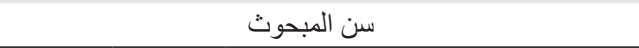 } \\
\hline$r_{0, V}$ & $\varepsilon \wedge$ & قليلة (10 - Y (Y) سنة & $r 1,0$ & 09 & صغار السن (דr- •0) سنة \\
\hline or,o & $1 \cdots$ & متوسطة (•r - م⿸广) سنة & $\varepsilon \wedge, \vee$ & 91 & متوسط السن( (0_-ب7) سنة \\
\hline$r \cdot, \wedge$ & rq & طويلة (ع ـ ـ ON) سنة & 19,1 & re & كبار السن (ع人_T) سنه \\
\hline \multicolumn{2}{|c|}{$r 0,07$} & 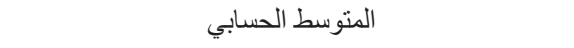 & \multicolumn{2}{|c|}{00,01} & 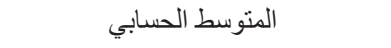 \\
\hline \multicolumn{2}{|c|}{ q,ru } & الانحر اف المعياري & \multicolumn{2}{|c|}{9,17} & الانحر اف المعياري \\
\hline \multicolumn{3}{|r|}{ أفر اد الأسرة العاملين بالزر اعة } & \multicolumn{3}{|r|}{ عدد الأبناء } \\
\hline .0 & 1 & قلبلة (•- 1 ) فرد & r & 01 & قليلة (1 - ؟) فرد \\
\hline $9 \leq, V$ & IVV & منوسطة (r - r) فرد & $\sum \vee, T$ & 19 & متوسطة (ع - 7) فرد \\
\hline$\varepsilon, \wedge$ & 9 & طويلة (ع ـ0) فرد & $r, \varepsilon$ & $\varepsilon$. & طويلة (V - (9) فرد \\
\hline \multicolumn{2}{|c|}{$1,0 r$} & 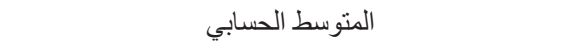 & \multicolumn{2}{|c|}{$\varepsilon, V \uparrow$} & 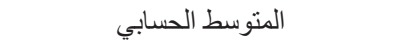 \\
\hline \multicolumn{2}{|c|}{$\cdot$, Tr } & الانحر اف المعياري & \multicolumn{2}{|c|}{$1,9 \leq$} & الانحر اف المعياري \\
\hline \multicolumn{3}{|r|}{ السعة الحيازية المزر عية } & \multicolumn{3}{|c|}{ المستوي التعليمي للمبحوث } \\
\hline$\wedge \Gamma, \varepsilon$ & 107 & صغيرة (V) - ( & $1 \cdot, \mathrm{V}$ & r. & (صفر) أمي \\
\hline $1 \%, 9$ & ry & 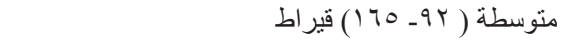 & $\varepsilon r, r$ & $\vee q$ & ( ) يقر أ ويكتب \\
\hline$r, r$ & $\circ$ & كبيرة ( צT ( - • ع Y) قير اط & $r v$, & 79 & 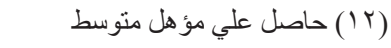 \\
\hline \multicolumn{2}{|c|}{$71, \times 1$} & المتوسط الحسابي & $\varepsilon, \wedge$ & 9 & ( ع 1) حاصل علي مؤهل فوق منوسط \\
\hline \multicolumn{2}{|c|}{$r q, \cdot 7$} & 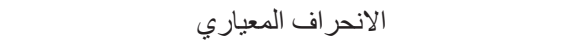 & $0, r$ & $1 \cdot$ & (1 1 ) حاصل علي مؤهل جامعي \\
\hline \multicolumn{3}{|r|}{ المعرفة بأعضاء الر ابطة } & \multicolumn{3}{|r|}{ 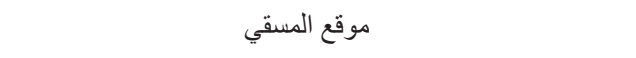 } \\
\hline \multirow[t]{2}{*}{$1 \cdots}$, & lAV & 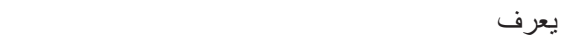 & $r 0, \Lambda$ & TV & (1 (') نهاية الترعة \\
\hline & & المعرفة بعدد أعضاء الر ابطة & $r \varepsilon, r$ & $7 \varepsilon$ & (r) وسط الترعة \\
\hline \multirow[t]{9}{*}{$1 \cdots}$, & IAV & ت بعرف & $r \cdot$ & 07 & (ץ) بداية الترعة \\
\hline & & & & & المتوسط الحسابي \\
\hline & & & & & الانحر اف المعياري \\
\hline & & & \multicolumn{3}{|c|}{ التعرض للمصادر المعلوماتية الزر اعية } \\
\hline & & & $r \leqslant, T$ & $\leqslant 7$ & منخفض (7-10) درجة \\
\hline & & & $T \varepsilon, V$ & $|r|$ & متوسط (ך ا_ץY) درجة \\
\hline & & & $1 \cdot, \mathrm{V}$ & $r$. & مرتفع ( \\
\hline & & & \multicolumn{2}{|c|}{11,01} & المتوسط الحسابي \\
\hline & & & \multicolumn{2}{|c|}{$\varepsilon, \varepsilon 0$} & الانحر اف المعياري \\
\hline
\end{tabular}

INV $=\dot{ن}$

المصدر: حسبث من استمار ات الاستبيان

جدول ץ. توزيع المبحوثين وفقاً لارجة قيامهم بمهامهم الإرشادية. .

\begin{tabular}{|c|c|c|c|c|}
\hline الانحياري & المستوسطي & $\%$ & عدد & درجة القيام \\
\hline \multirow{4}{*}{$\varepsilon, 17$} & \multirow{4}{*}{ or,,$\leq \varepsilon$} & $11, r$ & r) & 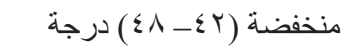 \\
\hline & & $V 7,0$ & $1 \leqslant r$ & منوسطة (9 (\&V) درجة \\
\hline & & Ir, r & r & 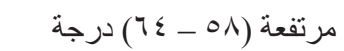 \\
\hline & & $1 \cdots$, & $11 \mathrm{~V}$ & الإجمالي \\
\hline
\end{tabular}

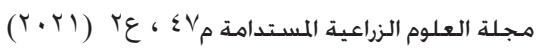


بمتوسط مرجح بلغ بآ ب درجة، يليه مهمة إيداع المبالغ المالية

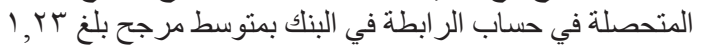

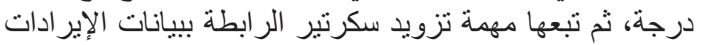

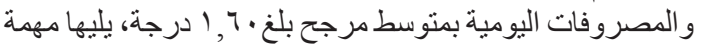

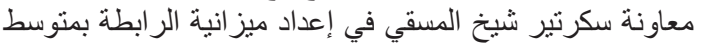

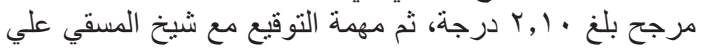
الثيكات البنكية بالمبالغ المالية المسحوبة بمتوسط مرجح بلغ لئغ

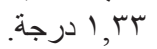

وأوضحت النتائج بجدول (๕) وجود تباين بين المبحوثين في

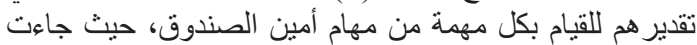

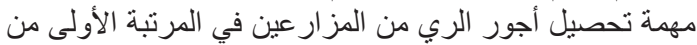

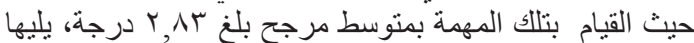

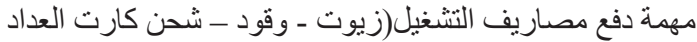

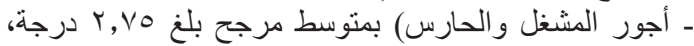

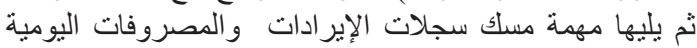

جدول ؛ ـ توزيع المبحوثين وفق قيامهم بالمهام المتعلقة بأعضاء الروابط الخاصة بهم

\begin{tabular}{|c|c|c|c|c|c|}
\hline المرجح & 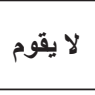 & يقوم الي & 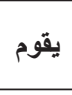 & مهام أعضاء الروابط & s \\
\hline & & & & شيخ المسقي & 1 \\
\hline$r, \wedge)$ & 1 & rt & 101 & رئاسة الر ابطة وتحديد مواعيد الإجنماعات الثهرية & \\
\hline$r, Y)$ & $\wedge$ & rq & $1 \leqslant$ & تحديد الاجنماعات السنوية للجمعية العمومية للر ابطة و الإعداد لأي إجنماع طارئ & \\
\hline r, 10 & ir & $\varepsilon r$ & rra & متابعة تنفيذ جداول المطارفة (الموارشة) & \\
\hline $1, \varepsilon \pi$ & Irt & $\varepsilon \vee$ & iv & رقابة قادة المحابس ومساعدتهم في حل المشاكل التي قد تنشأ علي المروي & \\
\hline \multirow[t]{2}{*}{ r,01 } & $r \leq$ & $\leqslant \varepsilon$ & 119 & تمثيل الر ابطة قبل الغير & \\
\hline & & & & 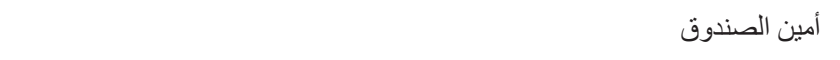 & r \\
\hline r,^ז & v & 11 & 174 & تحصيل أجور الري من المزارعين & \\
\hline r, vo & $\wedge$ & $r \cdot$ & $1 \leq 9$ & دفع مصاريف التشغيل(زيوتـ وقود ـشحن كارت العدادـ اجور المشغل والحارس) & \\
\hline r,tr & ir & $\varepsilon v$ & IrA & مسك سجلات الإير ادات و المصروفات اليومية & \\
\hline $1, r$ & 101 & rq & v & إيداع المبالغ المالية المتحصلة في حساب الر ابطة في البنك & \\
\hline 1,7 & $1 \cdot \varepsilon$ & $0 \leqslant$ & rq & تزويد سكرتير الرابطة ببيانات الإيرادات و المصروفات اليومية & \\
\hline r,. & $\leq 9$ & v^ & 7. & معاونة سكرتيرشيخ المسقي في إعداد ميز انية الر ابطة الر ابطة & \\
\hline \multirow[t]{2}{*}{ זr } & $1 \pi$ & 0. & 1 & التوقيع مع شيخ المسقي علي الثيكات البنكية بالمبالغ المالية المسحوبة & \\
\hline & & & & سكرتير الرابطة & r \\
\hline$r, 01$ & 11 & rq & irv & يحتفظ بجميع بيانات المسقي & \\
\hline 1,0 & 114 & $0 \leqslant$ & r. & استلام جميع الايصالات من مشغل المسقي وقيدها في سجل خاص & \\
\hline$r, \varepsilon$. & rı & ov & $1 \cdot r$ & يمكن اعضاء الر ابطة من الاطلاع علي السجلات في اي وقت & \\
\hline r, ro & $\varepsilon$ & 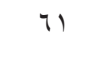 & 人т & يدون في سجل الاير اد اليومي و الثهري للمسقي & \\
\hline r,ro & rv & $\leqslant \vee$ & $1 \cdot r$ & يقبد في السجل جميع المبالغ المنصرفة علي التشغيل و الصبانة & \\
\hline$r, \varepsilon r$ & rq & $\leq 9$ & 1.9 & يقوم بإعداد الموقف المالي يعرضة علي الر ابطة في الاجتماع الثهري & \\
\hline \multirow[t]{2}{*}{$1, \wedge 1$} & $v \varepsilon$ & vo & rی & يقيد في السجل انواع المحاصيل المزروعة و المساحات التي تم ريها & \\
\hline & & & & مشغل المحطة & $\varepsilon$ \\
\hline r,१९ & 1 & $\cdot$ & 114 & تشغيل الطلمبة لأي عضو حسب تعليمات الر ابطة & \\
\hline r,Ar & . & $r \varepsilon$ & lor & استلام الزيوت و الوقوداللازمة لتشغيل الطلمبة & \\
\hline$r, Y)$ & 1. & ro & $1 \leqslant r$ & مر اقبة الزيوت و الوقود ومياة التبريد للطلمبة & \\
\hline $1, r$. & $1 \leqslant$. & re & 1. & تقيد ساعات التشغيل ت & \\
\hline $1, r v$ & $1 \leq 7$ & Ir & ru & تقبد اسماء الزر اع الذي تم ري ار اضيهم و المساحات التي تم ريها & \\
\hline
\end{tabular}

المصدر: حسبت من استمار ات الاستبيان. 
بمهمة تقييد أسماء الزراع الذي تم ري أر اضيهم و المساحات التي

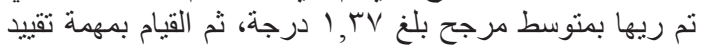

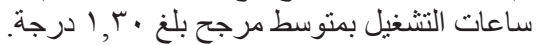

ثالثاً: المشكلات التي تواجه أعضاء روابط مستخدمي مياه

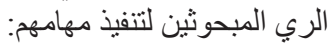

(أ) المشكلات الخاصة بالنو احي المالية:

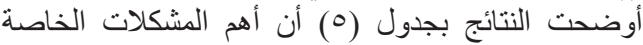

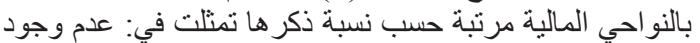

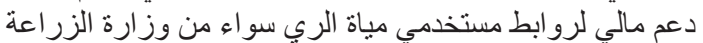

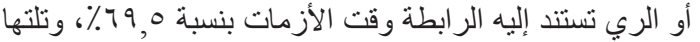

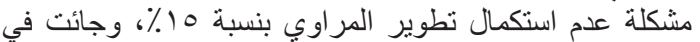

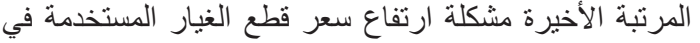

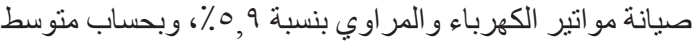

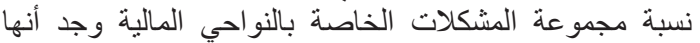

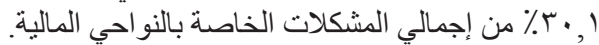

$$
\text { (ب) مشاكل خاصة بالصيانة: }
$$

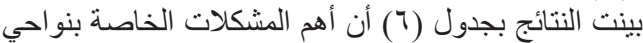

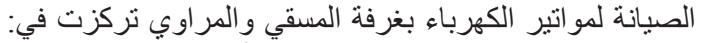

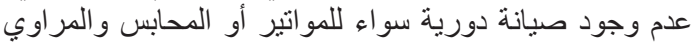

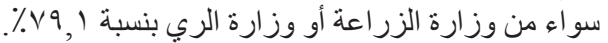

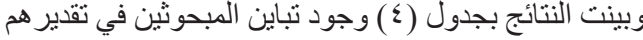

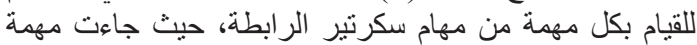

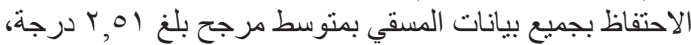

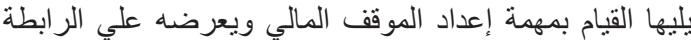

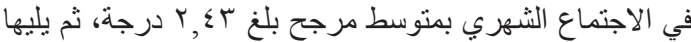

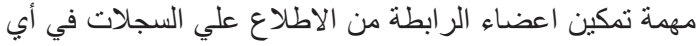

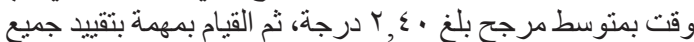

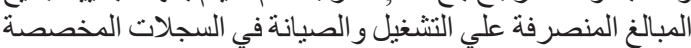

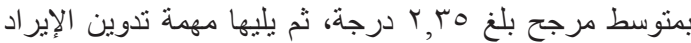

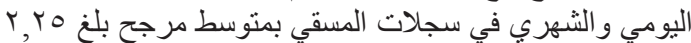

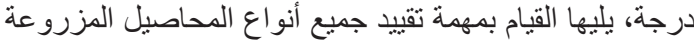

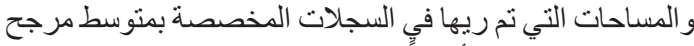

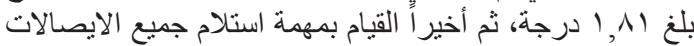

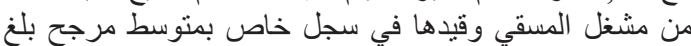

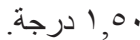

وأظهرت النتائج بجدول (ع) وجود تباين المبحوثين في

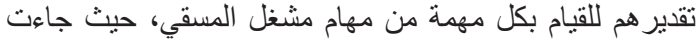

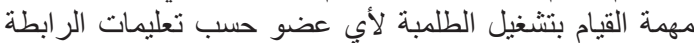

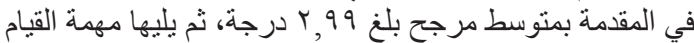

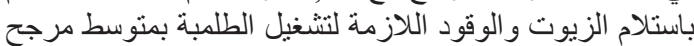

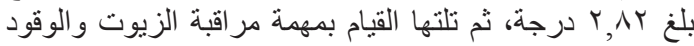

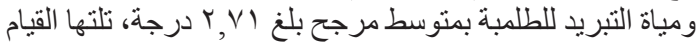

جدول •. توزيع المبحوثين وفق ذكرهم لأهم المشكلات المالية

\begin{tabular}{cccccc}
\hline & & \\
\hline \\
\end{tabular}

المصدر: حسبت من استمار ات الاستبيان.

جدول 7. توزيع المبحوثين وفق لذكرهم لأهم مشاكل الصيانة

\begin{tabular}{|c|c|c|c|c|}
\hline متوسط نسبة مجموعة & $\%$ & 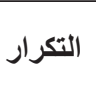 & 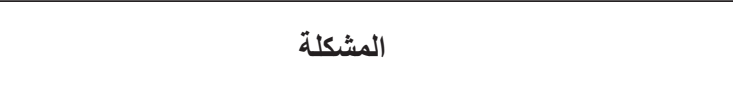 & م \\
\hline \multirow{6}{*}{07,0} & 71,0 & 110 & انتشار سرقة المحابس و المو اتير و الطلمبات & 1 \\
\hline & $\vee q, 1$ & $1 \leqslant \wedge$ & عدم وجود صيانة دورية سواء للمو اتير أو المحابس و المر اوي & r \\
\hline & 09,0 & $11 \mathrm{r}$ & عدم وجود فنيين مدربين علي إصلاح المر اوي و المو اتير & r \\
\hline & Ir, r & rth & عدم وجود مر اكز ورش للصيانة & $\varepsilon$ \\
\hline & $V_{r}, r$ & irt & انهيار جسور الترع & 0 \\
\hline & or, § & $1 \ldots$ & انخفاض منسوب قاع الترع مع ثبات منسوب ماسورة بيارة المسقي & 7 \\
\hline
\end{tabular}

المصدر: حسبت من استمار ات الاستبيان. 
ثـ المشكلات الخاصة بنو احي تسويق المحاصيل الزر اعية:

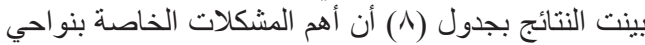

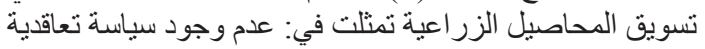

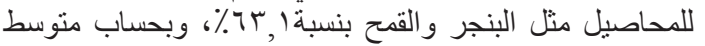

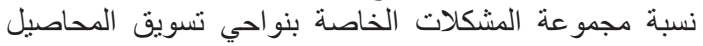

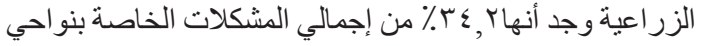
تسويق المحاصيل الزر اعية. ج- المشكلات الخاصة بالنو احي الإدارية:

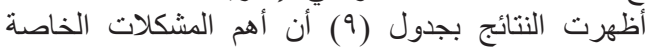

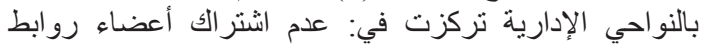

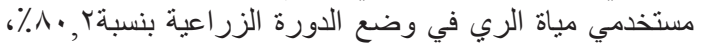

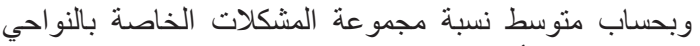

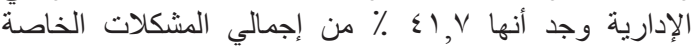
بالنواحي الإدارية.
وفي المرنبة الثانية مشكلة إنهيار جسور الترع بنسبة

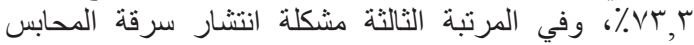

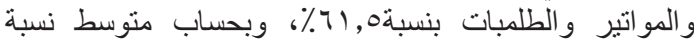

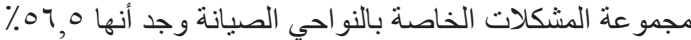
من إجمالي المشكلات الخاصة بنواحي الصبانة لمواتير الكهرباء

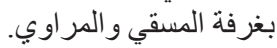

تـ مشكلات خاصة بالميكنة الزر اعية وتحسين التربة:

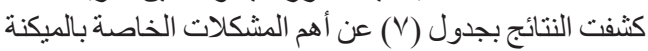

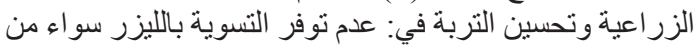

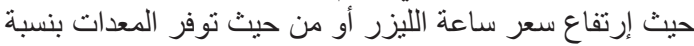

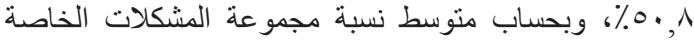

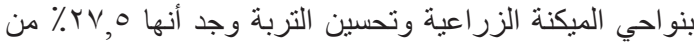

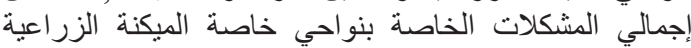
وتحسين التربة.

جدول V. توزيع المبحوثين وفق لأكر هم لأهم المشكلات الخاصة بالميكنة الزراعية وتحسين التربة

\begin{tabular}{cccccc}
\hline & \\
\hline \\
\end{tabular}

المصدر: حسبت من استمار ات الاستبيان.

جدول ^. توزيع المبحوثين وفق لذكرهم لأهم المشكلات الخاصة بنواحي تسويق المحاصيل الزراعية

\begin{tabular}{|c|c|c|c|c|}
\hline متوسط نسبة مجموعة & $\%$ & 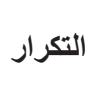 & 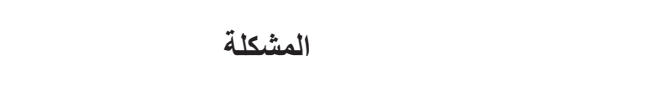 & م \\
\hline & $7 r, 1$ & 111 & عدم وجود سياسة تعاقدية للمحاصيل مثل البنجر و القمح & 1 \\
\hline \multirow[t]{2}{*}{$\% r \varepsilon, r$} & $r V, \wedge$ & or & عدم وجود هيئة أوجهة مختصة بتسويق المحاصبل الزر اعية & r \\
\hline & $11, \mathrm{~V}$ & rr & عدم توفر المعلومات التسويقية قبل زر اعة المحاصيل & r \\
\hline
\end{tabular}

المصدر: حسبت من استمار ات الاستبيان.

جدول 9. توزيع المبحوثين وفت لأكرهم لأهم المشكلات المشكلات الخاصة بالنواحي الإدارية. .

\begin{tabular}{|c|c|c|c|c|}
\hline مجموعة المشكلات & $\%$ & التكرار & المشكلات & s \\
\hline \multirow{5}{*}{$\varepsilon 1, \vee$} & $\Lambda \cdot, r$ & 10. & عدم إثتر الك أعضاء رو ابط مستخدمي مياة الري في وضع الدورة الزر اعية & 1 \\
\hline & $70, r$ & Irt & عدم وجود تبار مستمر من مياة الري في الترع & r \\
\hline & $\varepsilon r, \wedge$ & $\wedge$. & عدم إنتظام مناوبات الري في الترع & r \\
\hline & $1 т, \varepsilon$ & ro & اعتماد أعضاء الر ابطة في إدارة المسقي علي الخبرات السابقة & $\varepsilon$ \\
\hline & V & Ir & عدم تدريب اعضاء الر ابطة علي كيفية الإدارة لشؤن الر ابطة & 0 \\
\hline
\end{tabular}


بينت النتائج بجدول (Y l ) أن أهم مفترحات المبحوثين للتغلب

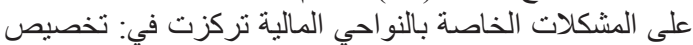

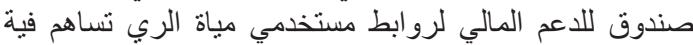

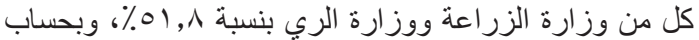

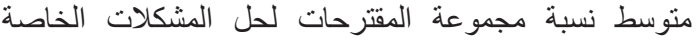

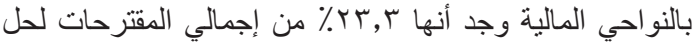
المشكلات الخاصة بالنو احي المالية.

r- مقترحات المبحوثين لمو اجهة المشكلات المتعلقة بنواحي الصبانة : البر كثفت النتائج بجدول (Y I ( ) عن أن أهم مقترحات المبحوثين

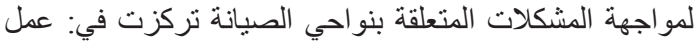

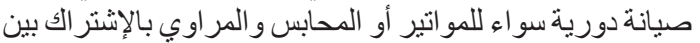

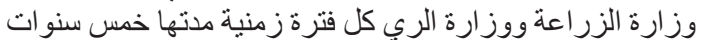

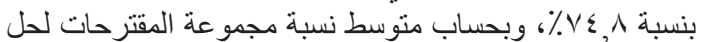

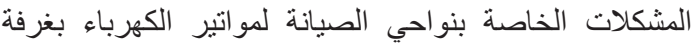

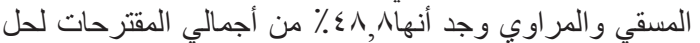

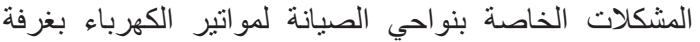

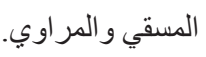

r- مقترحات المبحوثين لحل المشكلات الخاصة بنواحي الميكنة الزر اعية وتحسين التربة:

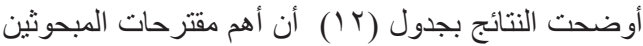

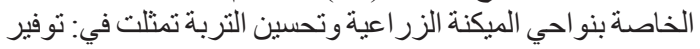

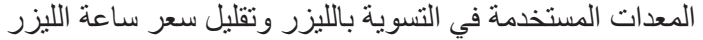

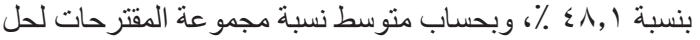

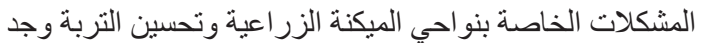

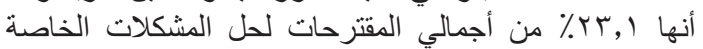
بنو احي الميكنة الزر اعية وتحسي المبئ التربة.
ح ـ المشكلات الخاصة بمستلزمات الإنتاج الزراعي:

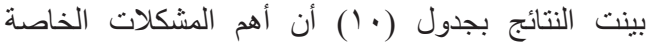

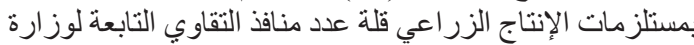

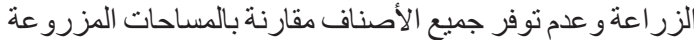

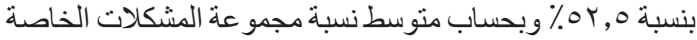

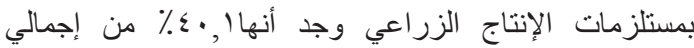

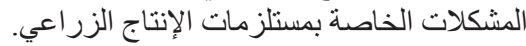

خ - المشكلات الخاصة بنو احي البحوث الزر اعية والإرشاد

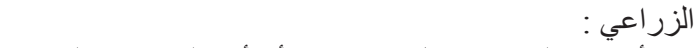

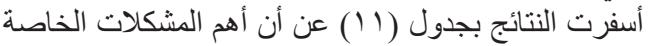

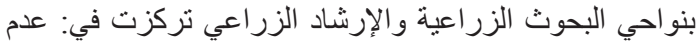

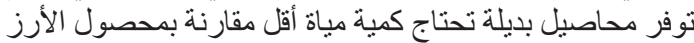

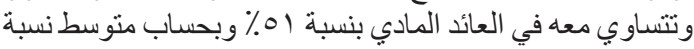

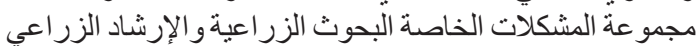

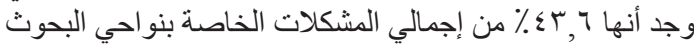
الزر اعية والإرشاد الزئ إعي.

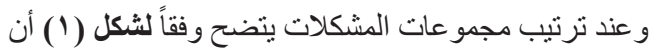

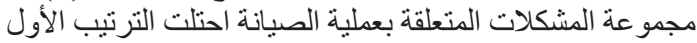

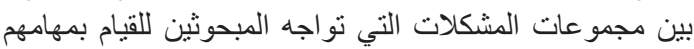
بنسبة متوسطة بلغت 07 \%

رابعاً: اقترحات أعضاء روابط مستخدمي المياه المبحوثين لحل المشكلات التي تو اجهم أثناء القيام بدور هم في إدارة الر ابطة: 1ـ مقترحات المبحوثين لحل المشكلات الخاصة بالنواحي

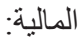

جلول • 1 ـ توزيع المبحوثين وفق لذكر هم لأهم المشكلات المشكلات الخاصة بمستلزمات الإنتاج الزراعي

\begin{tabular}{|c|c|c|c|c|}
\hline متوسط نسبَّه مجموعة & $\%$ & التكرار & المشكلة & P \\
\hline \multirow[t]{2}{*}{$\varepsilon \cdot, r$} & Or,o & 91 & ققارنة بدالمساحات المزافر التقاوي التابعة لوزارة الزراعة و عدم توفر جميع الأصناف & 1 \\
\hline & $r V, \Lambda$ & or & و المخصمبات بأسعار مناسبة الإنتاج من الأسمدة والجبس الزراعي و المبيدات & r \\
\hline
\end{tabular}

جدول 11 ـ توزيع المبحوثين وفق لذكرهم لأهم المشكلات الخاصة بنواحي البحوث والإرشاد الزراعي

\begin{tabular}{|c|c|c|c|c|}
\hline 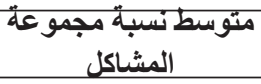 & $\%$ & 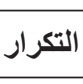 & 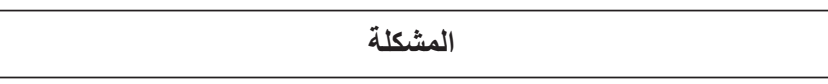 & م \\
\hline \multirow{3}{*}{$\varepsilon r, \vee$} & $01, r$ & 97 & معة في العائد الماديل بديلة تحتاج كمية مياة أقل مقارنة بمحصول الأرزوتتساوي & 1 \\
\hline & $\leq \cdot, 1$ & vo & عدم المرور المستمر من المرشدين علي المحاصيل في فترات النمو المختلفة & r \\
\hline & $r q, 7$ & $V \varepsilon$ & قلة عدد الحقول الارشادية & $\Gamma$ \\
\hline
\end{tabular}

المصدر: حسبت من استمار ات الاستبيان.

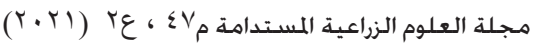


جدول ب ا. توزيع المبحوثين وفقاً لأهم مقترحاتهم التظلب على المشكلات المعوقة لمهامهم الإرشادية

\begin{tabular}{|c|c|c|c|c|}
\hline متوسطنسبة & $\%$ & عدد & المقترحات & s \\
\hline \multirow{6}{*}{$r$ re, } & & & مقترحات حل المشكلات الخاصة بالنواحي المالية: م & أ \\
\hline & $01, \wedge$ & १४ & و الريصيص صندوق للاعم المالي لروابط مستخدمي مياة الري تساهم فية كل من وزارتي الزر اعة & 1 \\
\hline & $\varepsilon, \wedge$ & 9 & توفير قطع الغيار المستخدمة في صيانة مواتير الكهرباء و المراوي بأسعار مناسبة & r \\
\hline & $1 \%, \varepsilon$ & ro & 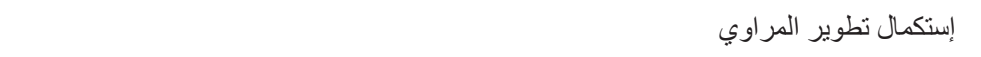 & r \\
\hline & & & مقترحات حل المشكلات الخاصة بنواحي الصيانة لمو اتير الكهرباء بغرفة المسقي والمراوي: & ب \\
\hline & $V \varepsilon, \wedge$ & $1 \leqslant \cdot$ & كل فترة صيانة دورية سواء للمو اتتير أو المحابس و المر اوي بالإشتر اك بين وزارتي الزر اعة والري & 1 \\
\hline \multirow[t]{5}{*}{$\varepsilon \wedge, \wedge$} & $\leq r, \Lambda$ & $\wedge$. & تالتريع للجمعية الزبين بالجمعيات الزراعية ليشرف كل فني هندسي علي عطيات الصيانة للري المطور & r \\
\hline & lr,r & rtr & عمل ورش للصيانة بالجمعيات الزر اعية يتوفر بها قطع الغيار لصيانة الري المطور بأسعار مناسبة & $r$ \\
\hline & $70, r$ & Irr & تطوير الترع سواء عن تبطين الترع أوتطوير هامواسير مدفونة & $\varepsilon$ \\
\hline & & & مقترحات حل المشكلات الخاصة بنو احي الميكنة الزر اعية وتحسين التربة: & $ت$ \\
\hline & $\varepsilon \wedge, 1$ & 9. & توفير المعدات المستخدمة في التسوية بالليزر وتقليل سعرساعة الليزر & 1 \\
\hline \multirow{9}{*}{$r+, 1$} & 19,1 & re & توفير الات ومعدات زر اعية تتناسب مع المساحات الصغيرة & r \\
\hline & $1 \cdot, v$ & $r \cdot$ & تفعيل مشروع تحسين الأر اضي الزر اعية الخاص بالحرث تحت التربة بأسعار مناسبة & r \\
\hline & $1 \%, 9$ & r4 & تحسين شبكات الصرف المغطي سو اء بصيانتها أوبإستبدالها بشبكات صرف حديثة & $\varepsilon$ \\
\hline & & & مقترحات حل المشكلات الخاصة بنو احي تسويق المحاصيل الزر اعية: & $ث$ \\
\hline & $O V, r$ & $1 \cdot v$ & أنباع سياسة تعاقدية لجميع المحاصيل الزر اعية مثل البنجر و القمح & 1 \\
\hline & $0, r$ & 1. & تفعيل التسويق التعاوني بتسويق المحاصيل الزر اعية بالجمعية الزر اعية & r \\
\hline & $11, \mathrm{~V}$ & rt & توفير المعلومات الخاصة بالأسعار المتوقعة للمحاصيل وتعلق بالجمعيات قبل زر اعة المحاصيل & r \\
\hline & & & مقترحات حل المشكلات الخاصة بالنواحي الإدارية: & ج \\
\hline & or, \& & $1 \ldots$ & محصبيق الدورة الزر اعية باثشتر الك أعضاء رو ابط مستخدمي مياة الري خاصة الصيفية لتحديد مساحة & 1 \\
\hline \multirow[t]{4}{*}{ rт,O } & $r v, \varepsilon$ & $v \cdot$ & 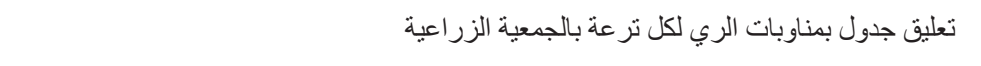 & r \\
\hline & $\wedge$, & 10 & تنظيم دور ات تدرييةتلأعضاء الروابط عن كيفية إدارة شؤن المسقي & r \\
\hline & $\mathrm{v}$, & ir & عدم تدريب اعضاء الر ابطة علي كيفية الإدارة لشؤن الرابطة & $\varepsilon$ \\
\hline & & & مقترحات حل المشكلات الخاصة بنو احي مستلزمات الإنتاج الزر اعي: & $د$ \\
\hline \multirow[t]{3}{*}{$r_{0,9}$} & $r \varepsilon, v$ & 70 & زيادة عدد منافذ التقاوي ليكون في كل جمعية منفذ للتقاوي يتوفر بها جميع الأصناف & 1 \\
\hline & $\mid v, 1$ & rt & توفير مستلزمات الإنتاج بأسعار مناسبة & r \\
\hline & & & مقترحات حل المشكلات الخاصة بنو احي البحوث الزر اعبة و الإرشاد الزر اعي: & j \\
\hline \multirow{3}{*}{$r \varepsilon, 0$} & ґ,, & vr & الأخذ بيد البحوث الزراعية لإيجاد محاصيل بديلة لمحصول الأرزوتتساوي معة في العائد المادي & 1 \\
\hline & rr, & 7. & المختلفة أخصائي المحاصيل بجهاز الإرشاد الزر اعي بالمرور علي المحاصيل في فنرات النمو & r \\
\hline & $r+1$ & r & التوسع في زياد عدد الحقول الارشادية & $r$ \\
\hline
\end{tabular}




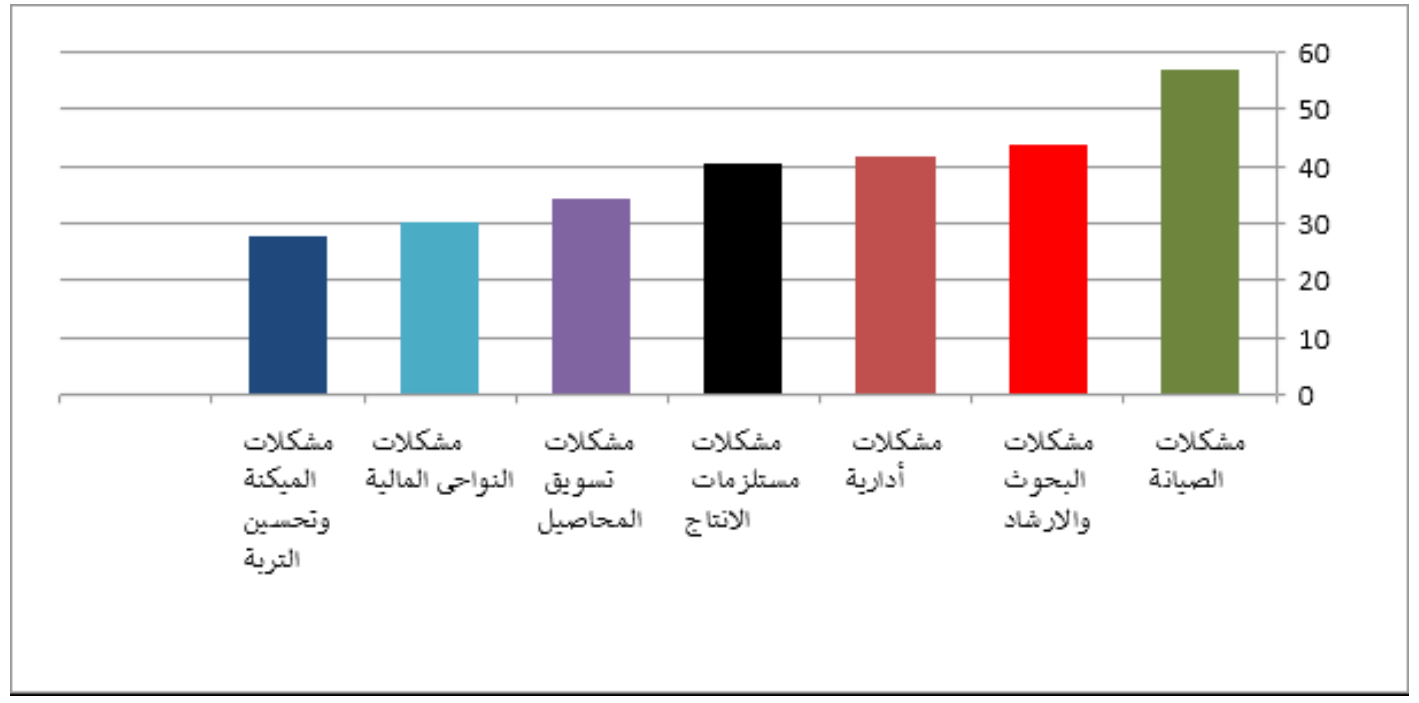

شكل 1. ترتيب المشكلات التي تواجة روابط مستخدمي مياة الري حسب أهميتها النسبية

والإرشاد الزراعي أهمها: الأخذ بيد البحوث الزراعية لإيجاد

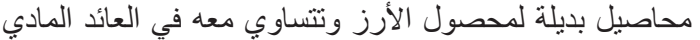

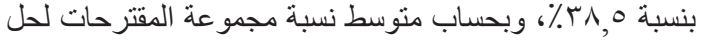

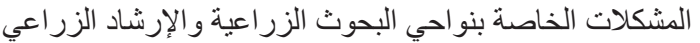

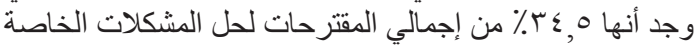

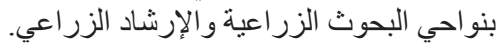

التوصيات :

بناء علي النتائج البحثية السابقة يمكن التوصية بما يلي:

ـ تقديم الدعم المالي و الفني و الإداري لرو ابط مستخدمي مياة الري

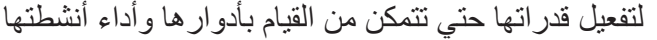
بفاعلية وتحقق أهدافها.

ـ العمل علي التنسيق بين وزارة الزراعة ووزارة الري لتقديم

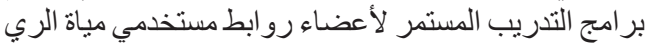

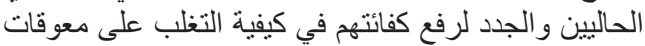

$$
\text { أدائهم لدور هم الإرشادي. }
$$

ـ اهتمام المسؤلون بوزارتي الزر اعة و الري علي توفير البيانات

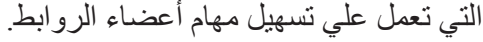

ـ أن يسمح المسؤلين بوزارة الزراعة بمشاركة أعضاء روابط الزئ

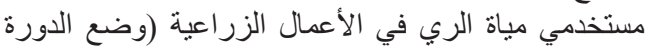
الزر اعية, أعمال التطهير).

التمويل Funding: لايوجد اى تمويل خارجى للار اسة مشاركة المؤلفين Author contribution : جميع المؤلفين شاركو ا فى اعداد وكتابة و مر اجعة و نشر البحث

تضارب المصالح Conflict of interest: لا يوجد تضارب مصالح بين المؤلفين
عـ مقترحات المبحوثين لحل المشكلات الخاصة بنواحي تسو يق المحاصيل الزر اعية: أسفرت النتائج بجدول (r I I ) عن أن أهم اقترحات المبحوثين

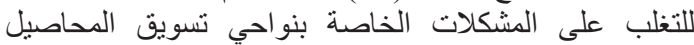
الزر اعية تمثلت في حول: أتباع سياسة تعاقدية لجميع المحاصيل

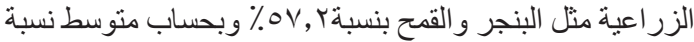

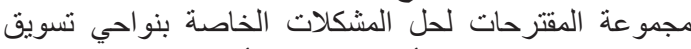

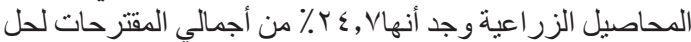
المشكلات الخاصة بنو احي تسويق المحاصيل الزيل الزر اعية. ــ مقترحات المبحوثين لحل المشكلات الخاصة بالنواحي أوضحت النتائج بجدول (r T) أن أهم اقترحات المبحوثين

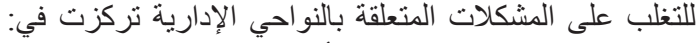

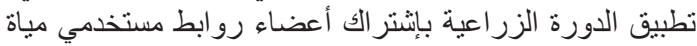

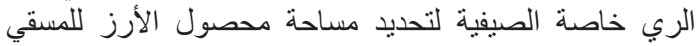

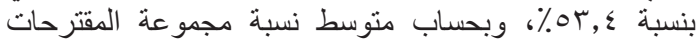

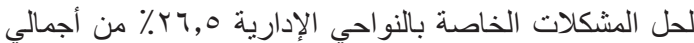
المقترحات لحل المشكلات الخاصة بالنوالنواحي الإدارية.

7- مقترحات المبحوثين لحل المشكلات الخاصة بنواحي

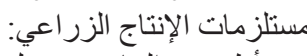

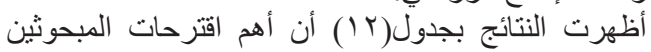

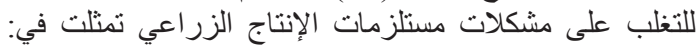

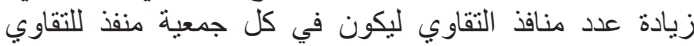

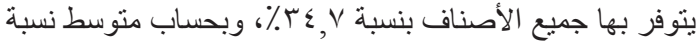

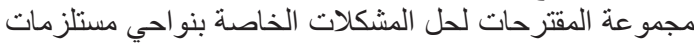

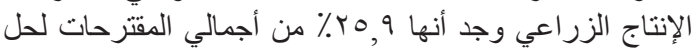

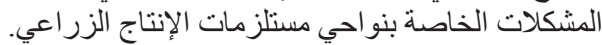

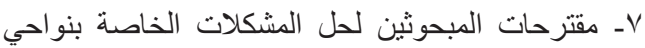

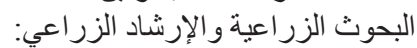

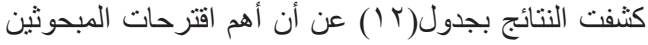

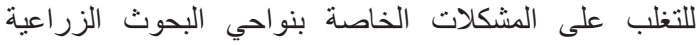




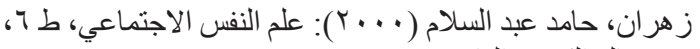

$$
\begin{aligned}
& \text { عالم الكتب، القاهرة. }
\end{aligned}
$$

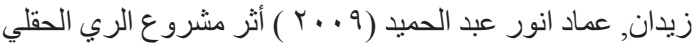

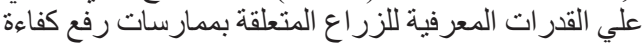

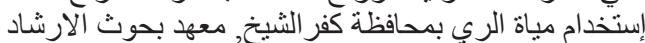

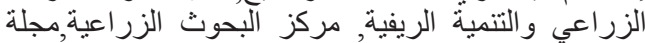

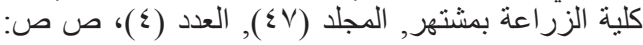
. $\varepsilon \leqslant-r V$

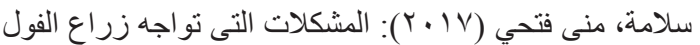

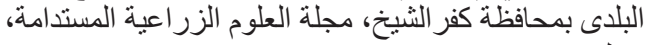

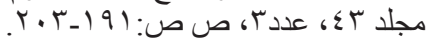

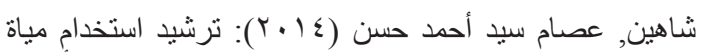

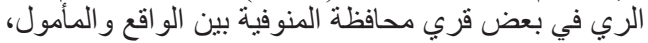
قسم الارُشاد الزر اعي، كلية الزر اعة، جامعة المنوفية.

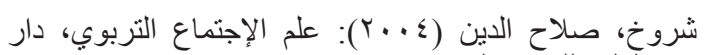

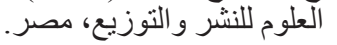

شمس الدين، عبداله شمس الدين (0. . ب): تحليل المشكلات و اتخاذ القرار ات الإدارية، دمشق، سوريا.

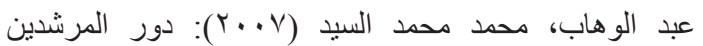

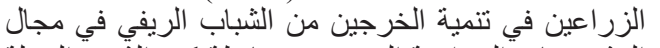

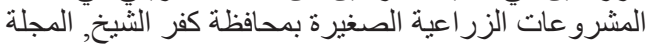

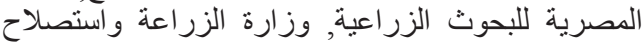

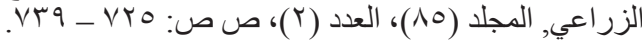
عبد الجواد، سامى أحمد (990 (1)): دور المنظمات الريفية في الرئي

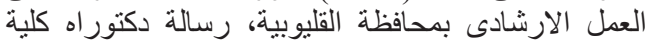
الزر اعة بمشتهر ، جامعة الزقازيق، فرئ فرعة بنها.

عبد المجيد، أشرف عبدالملك (ع ا ب ب): دراسة اقتصادية لكفاءة

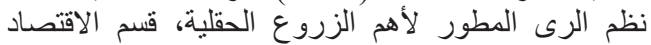
الزر اعى، كلية الزر اعة، جامعة كفر الثيخ.

عبد الهادي، نبيل (9 × ץ): مقدمة في علم الاجتماع التربوي, دار

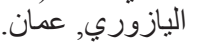

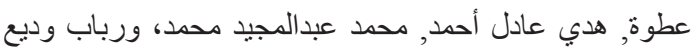

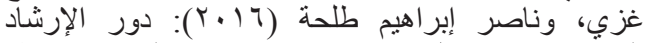

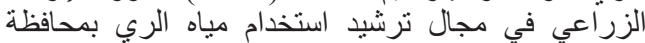

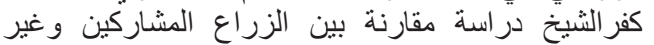

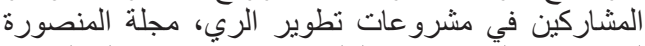

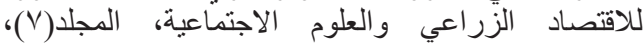

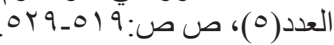

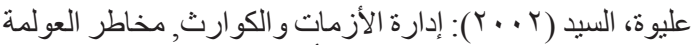
و الإرهاب الدولي، طب، دار الأمين للنشر و التوزيع، القاهرة.

عنتر ، محمد إبر اهيم (991 (1)): الأداء و المحددات لأدوار أعضاء

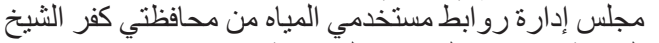

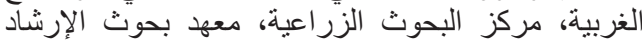

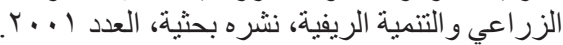

محافظة كفر الثيخ (1 ( • ب)): مركز المعلومات ودعم اتخاذ القرار.

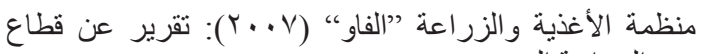

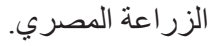

https//:Wikipedia org.
المراجع

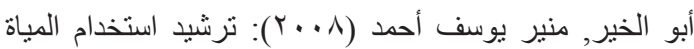

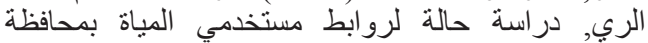
كفر ألثيخ, رسلة ماجستير, كلية الزر اعة, جامعة المنصورة.

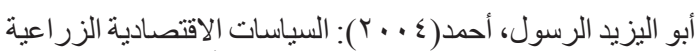
رؤي معاصرة, مكتبة بستان المعرفة، الأسكندرية.

الثرقاوي, مؤمن السيد نعيم(r ( ب r): الأثار التعليميةو الإجتماعية

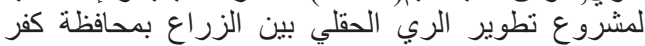

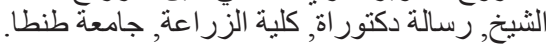

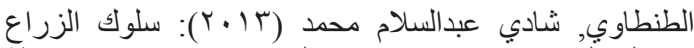

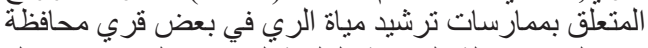

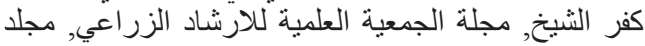
r

العادلي، أحمد السيد، سيد أحمد حافظ، حسن على شرشر (1997 ( ) ):

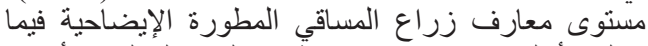

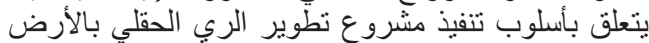

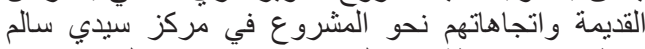

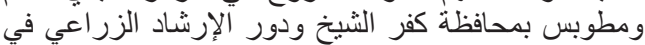

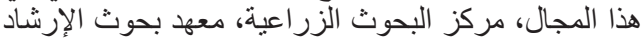

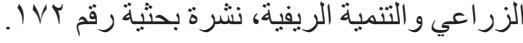

الوردي ,سليم علي ( 999 (1): إدارة الخطر و التأمين، مكتب الريم لئه للطبع، بغداد، العراق.

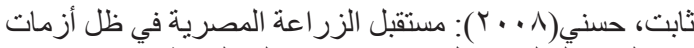

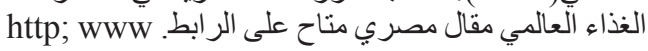
mass.com

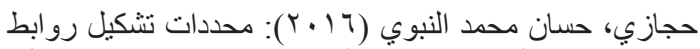

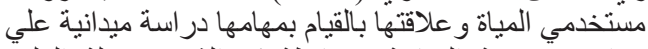

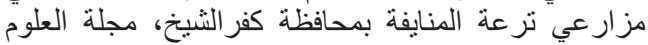

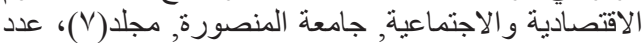

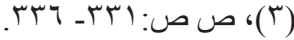

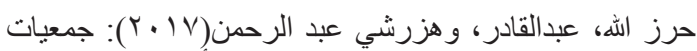

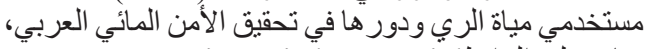

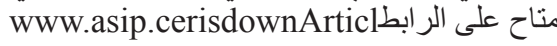

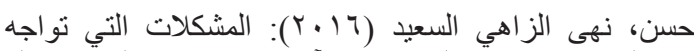

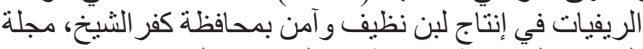

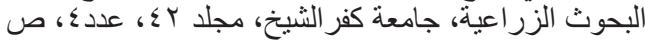
ص:

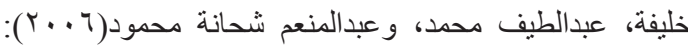
سيكلوجية الاتجاهات (المفهوم- القياس - التغير)، دار غريب اللنشر و التوزيع، القاهرة.

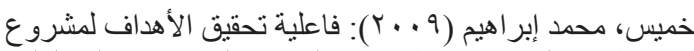

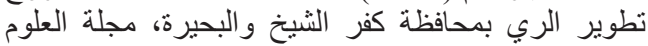

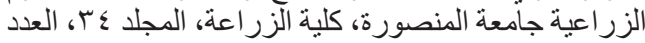

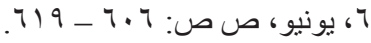

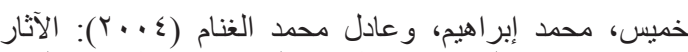

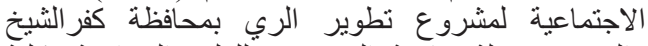

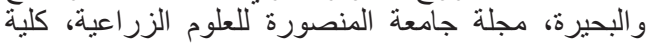

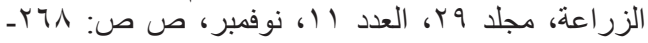
rVI 


\title{
The Problems Hindering Performance of the Water User Associations Members for their Extension Role at Some Villages, Kafr El -Sheikh Governorate
}

\author{
Adel I. Elhamoly ${ }^{1}$, Allam M. Eltantawy ${ }^{2}$ and Abd Elrahman A. Aydraosy ${ }^{\mathbf{1}}$ \\ ${ }^{1}$ Dept. of Agric. Economics, Faculty of Agriculture, Kafrelsheikh Uni., Egypt. \\ ${ }^{2}$ Agric. Extension \& Rural Development Institute, Agricultural Research Center, \\ Egypt.
}

\begin{abstract}
$\mathbf{T}$
HIS research aims to identify the problems that facing of the irrigation water user associations members in carrying out their role at Kafr El-Sheikh governorate. Desouq and Seidi Salem districts were chosen. Data were collected through a personal questionnaire after testing, from a random sample of 187 respondents, during the period from April to June 2020. Some statistical methods such as frequencies, percentage and mean were used to analyze the research data. The most important results of the search were $\mathrm{t}$ was found that $11.2 \%$ of the respondents performed their advisory role with a low degree, while $76.5 \%$ of them performed their counseling role with a moderate degree, while $12.3 \%$ of them performed their counseling role with a high degree. The problems of maintenance of electric motors were $56.5 \%$, the problems of agricultural research and agricultural extension by $43.6 \%$, the administrative problems by $41.7 \%$. Problems of agricultural production requirements by $40.1 \%$, problems of marketing agricultural crops by $34.2 \%$, financial problems by $30.1 \%$, and finally problems of agricultural mechanization and soil improvement by $27.5 \%$.
\end{abstract}

Key words: Problem, Administrative, Financial, Maintenance, Bonds, Water, Almisqa, watering, crises. 